\title{
Albert Mockel, Propos de littérature (1894) suivis de Stéphane Mallarmé, un héros (1899) et autres textes
}

\section{Mario Richter}

\section{(2) OpenEdition}

1 Journals

\section{Edizione digitale}

URL: http://journals.openedition.org/studifrancesi/7662

DOI: 10.4000/studifrancesi.7662

ISSN: 2421-5856

\section{Editore}

Rosenberg \& Sellier

\section{Edizione cartacea}

Data di pubblicazione: 1 décembre 2009

Paginazione: 655

ISSN: 0039-2944

\section{Notizia bibliografica digitale}

Mario Richter, «Albert Mockel, Propos de littérature (1894) suivis de Stéphane Mallarmé, un héros (1899)

et autres textes», Studi Francesi [Online], 159 (LIII | III) | 2009, online dal 30 novembre 2015, consultato il

09 janvier 2021. URL: http://journals.openedition.org/studifrancesi/7662 ; DOI: https://doi.org/

10.4000/studifrancesi.7662

Questo documento è stato generato automaticamente il 9 janvier 2021.

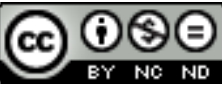

Studi Francesi è distribuita con Licenza Creative Commons Attribuzione - Non commerciale - Non opere derivate 4.0 Internazionale. 


\title{
Albert Mockel, Propos de littérature (1894) suivis de Stéphane Mallarmé, un héros (1899) et autres textes
}

\author{
Mario Richter
}

\section{NOTIZIA}

ALBERT MOCKEL, Propos de littérature (1894) suivis de Stéphane Mallarmé, un héros (1899) et autres textes, précédés d'une étude par Paul GORCEIX, Paris, Champion, 2009, pp. 286.

1 Riprendendo il testo di Mockel egregiamente pubblicato nel 1962 da Michel Otten col titolo Esthétique du Symbolisme, l'A. lo ripropone in questo libro col dichiarato intento di inserirlo nel contesto dell'opera del poeta simbolista belga e di chiarirne le finalità. Vi ha aggiunto, dello stesso autore, il saggio su Mallarmé, nonché un'interessante serie di altri scritti di natura teorica come À propos des Harmonistes (1887), La littérature des images (1887), Lettre à René Ghil (1889), Poésie et Idéalité (1905), Musique et Poésie (1914).

2 I Propos de littérature fanno vedere con quale impegno Mockel cercò di liberare il verso per consentire al poeta di attuare la sua aspirazione verso l'Ideale senza dover soggiacere a una forma prestabilita. Gorceix sottolinea che, sotto questo aspetto, la posizione di Mockel è quella di un moderno, aggiungendo che il poeta belga «a vu le problème esthétique et poétique qui se pose à sa génération, celui d'objectiver l'ineffable du moi, qui n'est accessibile que de manière discontinue, par le biais de la connaissance intuitive, dans un langage qui épouse l'idée au plus près» (p. 97). Non meno moderna è l'idea secondo cui l'opera d'arte, dovendo raggiungere risonanze misteriose e molteplici, possa rimanere alquanto incompiuta e imprecisa, in modo da suggerire più d'una interpretazione da parte del lettore. L'opera d'arte, sostiene Mockel, raggiunge con l'armonia da essa creata un valore ontologico, suscitando «le pressentiment du Dieu qui d'heure en heure se crée en notre vie». 
3 Gli studiosi del Simbolismo possono trovare riuniti in quest'opera gli elementi che conferiscono coerenza e unità critica a un movimento culturale di non facile definizione.

4 L'opera si conclude con una bibliografia delle opere consultate e un indice dei nomi. 